\title{
Growing Tomato Plantlets on Various Mixtures of Peat and Sand or Peat and Perlite. Note 1
}

\author{
Antonia Patruno, Luigi Cavazza*, Elio Cirillo \\ Dipartimento di Scienze e Tecnologie Agroambientali, Università di Bologna \\ Viale Fanin 44, 40127 Bologna, Italy
}

Received: 5 August 2005. Accepted: 16 March 2006

\begin{abstract}
Given the considerable interest in use of substrates derived from various mixtures in the nursery sector and in light of the enormous variety of possibilities offered by this technique, in contrast with the still small number of researches dedicated to this theme, this study was set out to examine in-depth the growing of tomato plantlets on peat-based substrates. Two series of peat mixtures were produced, one with sand and the other with perlite, with a volume ratio of the other two components with respect to the peat of 1:0, 2.5:1, 1:1 and 1:2.5. Tomato seedlings were cultivated for 30 or 25 days in small perforated pots containing these mixtures. The irrigation was calculated by weighing each pot daily, measuring the water lost by evaporation-transpiration, then just past an established lower threshold value bringing the water back up to a defined upper threshold. Two water regimes were compared in the sand series and three in the perlite series. Each was identified on the basis of the "absolute container capacity" and wilting point appropriately assessed for each substrate. The data observed were statistically analysed using the covariance technique to take account of the number of plants per pot. Measurements were taken on both the plants and substrates. In both series of mixtures, pots with pure peat were found to be superior. Production of dry matter and leaf surface area both decreased with a reduction in the peat fraction in the mixture. The often irregular results, frequently subject to interactions attributable to the water regime are puzzling and require further separate in-depth investigation. A $1.5-0.5 \mathrm{~cm}$ thick layer near the surface of the pots of pure peat or about $71 \%$ peat was untouched by the roots, probably due to drying out or salinization of this layer caused by the high porosity at least in the sand series. The salinity of the substrates after cultivation increases with the percentage of peat and, in the case of the peat, with the lowest water regime. The role of peat was found to be irreplaceable in growing tomato seedlings for transplant. It has an influence on salinity at the end of cultivation. The irrigation regime appears more complex and requires further analysis of the various components.
\end{abstract}

Key-words: peat-based mixtures, tomato plantlets growing, hydraulic peat characteristics.

\section{Introduction}

In modern nursery techniques, widespread use is made of appropriate substrates to prepare plantlets for transplant (Bragg and Chambers, 1988). These substrates are often obtained by mixing various materials with peat, such as sand, perlite or other mineral materials, or materials deriving from the composting of various organic residues. In general, the choice of the components in the mixtures and their proportions are decided completely empirically. On the other hand, faced with the numerous possibilities for different combinations, there are very few studies seriously examining aspects of this problem (Tepe, 1953; White, 1964; De Boodt et al.,
1974; Tesi, 1984; Tesi et al., 1985; Fisher, 1985; Gras, 1987; Morel et al., 2000; Lenzi et al., 2001). This research is a contribution to knowledge by considering the production of sown tomato seedlings up to an average height of about 10$15 \mathrm{~cm}$, comparing both a number of mixtures of peat and sand or peat and perlite in various ratios and the application of various volumes of water.

\section{Materials and methods}

The experiment was performed in a greenhouse using commercially-available white sphagnum moss peat (moist and closed in a bag), silica riv- 
er sand and commercially-available expanded perlite. These were used to obtain substrates consisting of a) pure peat, b) a mixture of 2.5 parts volume peat and one part volume of the other component (sand or perlite); c) a similar mixture with the two components in a 1:1 ratio and d) a final mixture with a ratio of 1:2.5. More details on the characteristics of these materials are given in Patruno et al., (2005). The plastic pots used were truncated cone, widening at the top as shown in Figure 1, with a total maximum volume of $501 \mathrm{~cm}^{3}$. The bottom of the pots was perforated with six $11 \mathrm{~mm}$ diameter holes. The bottom was covered with a disk of cotton cloth, then a layer of expanded clay (spheres of about 5-7 $\mathrm{mm}$ ), in turn covered with a second disk of cotton cloth. The pots were filled flush with the various substrates. They were then thoroughly wetted with deionised water and left to drain all excess water for 21 hours. Seeds of the tomato cultivar "Romano", pregerminated in Petri capsules on blotting paper with a rootlet of 1-3 mm were used. Five seeds were planted per pot, lightly covered with soil. The definitive emergence in the pots of the two series of trials was good but not perfect. To establish the irrigation regimes to be compared, firstly the container $\mathrm{ca}$ pacity $\left(C_{\mathrm{c}}\right)$ was considered. This is defined as, starting from saturation, the amount of water retained in the pot after drainage has ceased. This parameter, calculated for each pot, differs conceptually from the traditional "water field capacity" for a number of reasons. Firstly, it is expressed as the total volume of water per pot (and therefore not as a percentage of dry soil), but above all because it represents a water equilibrium for the individual pot, while the field capacity refers to a transient condition which is assumed to be valid for a certain time after wetting.

As the lower limit for the availability of water for the plants, it is conventional to consider the so-called wilting point (WP, conventionally represented by the moisture at a matrix potential of $-1500 \mathrm{kPa}$, expressed as the percentage weight of the dry matter). For peat, the $W P$ was previously determined as $1.1 \%$ of dry weight. For the sand, $W P$ was negligible, while for the perlite, whose composition varies considerably depending on the batch, it was decided to assume a $W P$ value of $50 \%$ that of the peat. For the various mixtures with perlite, the $W P$ was

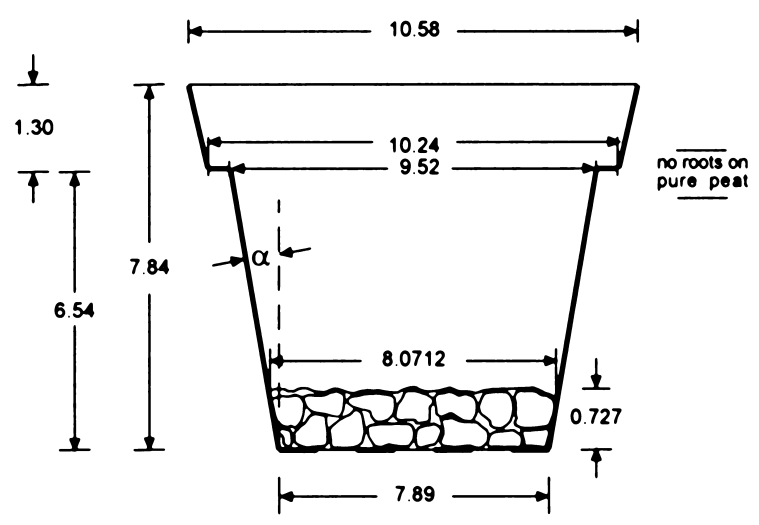

Figure 1. Size of pots and information on the visual development of the roots.

calculated according to the algorithm: $W P_{\mathrm{x}}=\left(f_{\mathrm{p}}\right.$ $\left.\times W P_{\mathrm{p}}\right)+0.5\left(f_{\mathrm{P}} \times W P_{\mathrm{p}}\right)$ where: $W P_{\mathrm{x}}$ refers to the mixture; $f_{\mathrm{p}}$ and $f_{\mathrm{P}}$ are the fractions of peat and perlite in the mixture; and $W P_{\mathrm{p}}$ is the $W P$ of the peat. In the peat-sand series, no value was attributed to the WP of the sand in the mixture. Transformation of the term expressed as mass of water over mass of dry matter $(w)$ to the more convenient volume of water over total volume of soil $(\theta)$ was obtained by multiplying the various values of $W P$ as $w$ by the bulk density of the mixtures in the individual pots (tab.1), thus obtaining $W P_{\theta}$. When $C_{\mathrm{c}}$ and $W P_{\theta}$ are known, the so-called "maximum available water" $\left(A W C_{\theta}=C_{\mathrm{c}}-W P_{\theta}\right)$ can be calculated, also expressed as a volume fraction (it should be borne in mind that of this $A W C$, a certain part may be used by the plant without affecting the intensity of transpiration, while the last part may lead to a reduction in transpiration). The relationships between $C_{\mathrm{c}}, W P_{\theta}$ and $A W C_{\theta}$ are illustrated in Figure 2.

Once these parameters had been established, the three irrigation regimes compared were defined by both upper water threshold $\left(\theta_{\mathrm{u}}\right)$ and lower water threshold $\left(\theta_{1}\right)$ as follows:

- $\mathrm{I}_{3}$ (= abundant), starting from $C_{\mathrm{c}}\left(=\theta_{\mathrm{u}},\right)$ allowing the water content in the pots to drop to half the $A W C_{\theta}$ as a result of evaporation and transpiration $\left(\theta_{1}\right)$, then topping up each time to $C_{\mathrm{c}}$;

- $\mathrm{I}_{2}$ (= intermediate) allowing the water content in the pot to drop to one-third of the $A W C_{\theta}\left(=\theta_{1}\right)$ and then topping up each time to two thirds of the $A W C_{\theta}\left(=\theta_{\mathrm{u}}\right)$. 

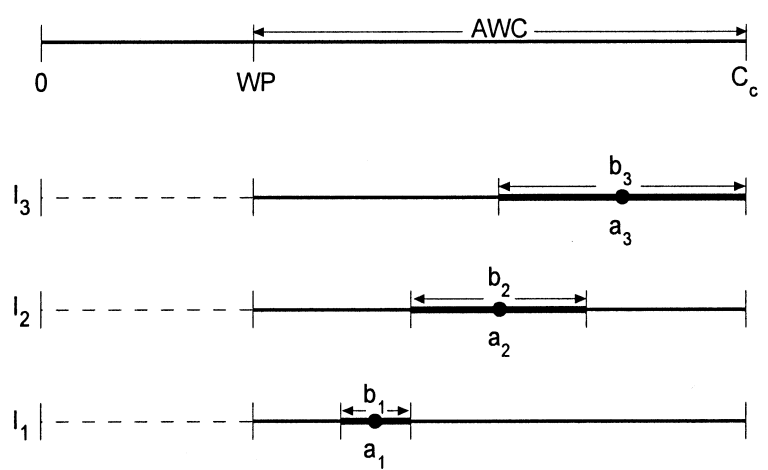

Figure 2. Diagram showing the choice of parameters $\left(C_{\mathrm{c}}\right.$, $\left.W P_{\theta}, A W C_{\theta}\right)$ and irrigation programme adopted $\left(\mathrm{I}_{3}, \mathrm{I}_{2}, \mathrm{I}_{1}\right)$; parameters $a$ and $b$ of each water regime.

- $\mathrm{I}_{1}(=$ low) allowing the water content to drop to one sixth of the $A W C_{\theta}\left(=\theta_{1}\right)$ and then topping up each time to one-third of the $A W$ $C_{\theta}\left(=\theta_{\mathrm{u}}\right)$. These "theoretical" irrigation regimes were adopted in applying water to the pots throughout the cycle, and are described in Figure 2. Each of these theoretical irrigation regimes is characterised by two parameters: a) mean soil moisture $\left(\bar{\theta}=\left(\theta_{\mathrm{u}}\right.\right.$ $\left.+\theta_{1}\right) / 2$.)) in the interval between the irrigation upper threshold and the lower threshold (in other words, between one watering and the next), and b) the range of moisture variation $\Delta \theta\left(=\theta_{\mathrm{u}}-\theta_{1}\right)$ between the two theoretically predicted extremes (from the irrigation upper threshold to the lower threshold value). These two parameters were chosen on the basis of intuition, trying to compensate for possible stress caused by a low value of $\bar{\theta}$ (i.e. small parameter $a$ ), or greater irrigation frequency (i.e. small $b$ ). As can be predicted, this reduced the differentiation between the three regimes in terms of crop performance. Table 1 shows the parameters and thresholds for the various mixtures and theoretical irrigation regimes compared.

In practice, all the variables required to manage the pots were expressed as mass of water (density $=1$ ) weighing the pots daily ${ }^{1}$.

When the weight of the pot dropped below

1 The effect of the plant gradual growth on the water consumption determined by pot weighing is negligible at the end of experiment the plant dry weight of the order of less than $10^{-3}$ the pot weight. the established threshold, it was brought up to the upper limit by adding deionised water. Each day, a certain number of pots were obviously found to be somewhat below the threshold and required bringing exactly up to the top limit. This meant that actual water consumption was slightly higher than the theoretical predictions.

For the first series of trials (with sand), three replications were established. However, given doubts as to whether the application of suitable fertiliser to the pots was appropriate (fearing that this might in part mask the effects of the peat fraction and irrigation), it was decided to use two replications without fertiliser, sacrificing the third to be fertilised (and so loosing almost entirely the opportunity of a statistical analysis of its resulting data). The results of this first trial with sand suggested that fertilising should be extended to the two replications in the subsequent series with perlite. The advantage of this solution will appear clearer in paper 2 .

During the trials which lasted respectively 30 and 25 days (a little less in the second cycle due to a slight increase in ambient temperature), periodic measurements were made of the number of plantlets per pot, water consumption, the number of leaves per pot and mean height (approximate) of the plantlets in each pot. At the end of the trial for the first series, peat-sand, it was decided to photograph the blocks of soil extracted from the pots in order to evaluate, although descriptively, certain complementary data on the distribution of the root system. For each pot, the following measurements were then taken: fresh weight, dry weight of the above ground part of the plantlets (cut off at the hypocotyl) and of the roots (after isolating them and cleaning them of substrate as far as possible), total leaf area (using an Li-Cor, Model 3100 Area Meter device), mean height of the collar to the top of the plant and, for the perlite series, diameter of the stem above the collar. After pulling up the plants, the following measurements were made on the substrate: residual moisture, electrical conductivity of the 1:2.5 aqueous extract, the $\mathrm{pH}$ of the extract.

Statistical analysis of the data was complicated by the variability of the number of plants per pot and therefore, for all the characteristics examined (except height and measurements on the soil) covariance analysis with respect to the 
Table 1. Determination of the three watering regimes.

\begin{tabular}{|c|c|c|c|c|c|c|c|c|c|}
\hline \multirow[t]{4}{*}{ Main characteristics } & & \multicolumn{4}{|c|}{ volume ratio for the sand series } & \multicolumn{4}{|c|}{ volume ratio for perlite series } \\
\hline & & $1: 0$ & $2,5: 1$ & $1: 1$ & $1: 2.5$ & $1: 0$ & $2,5: 1$ & $1: 1$ & $1: 2.5$ \\
\hline & & \multicolumn{4}{|c|}{$\%$ of peat in the substrate } & \multicolumn{4}{|c|}{$\%$ of peat in the substrate } \\
\hline & & 100 & 71.4 & 50 & 28,6 & 100 & 71.4 & 50 & 28.6 \\
\hline 1 Container capacity $\left(\mathrm{C}_{\mathrm{c}}=\theta_{\mathrm{cc}}\right)$ & $\mathrm{cm}^{3} /$ pot & 168.6 & 195.3 & 186.9 & 184.3 & 190.6 & 180.0 & 147.6 & 124.1 \\
\hline 2 Final soil volume & $\mathrm{cm}^{3} /$ pot & 337.7 & 316.7 & 351.3 & 372.9 & 356.6 & 351.2 & 381.9 & 423.3 \\
\hline $\begin{array}{l}3 \text { Corresponding volumetric } \\
\text { water content } \\
4 \text { Weight fraction of dry peat in }\end{array}$ & $\theta_{\mathrm{cc}}(\%)$ & 50.0 & 61.7 & 53.2 & 49.4 & 53.4 & 51.3 & 38.6 & 29.3 \\
\hline mixture & - & 1 & 0.1529 & 0.0674 & 0.0281 & 1 & 0.8075 & 0.6950 & 0.6020 \\
\hline 5 Final bulk density of mixture & $\mathrm{t} \mathrm{m}^{-3}$ & 0.1316 & 0.6259 & 0.9300 & 1.1829 & 0.1234 & 0.1365 & 0.1423 & 0.1402 \\
\hline 6 Wilting point & $\theta_{\text {w.p. }}(\%)$ & 14.48 & 10.53 & 6.90 & 3.66 & 13.57 & 12.12 & 10.88 & 9.28 \\
\hline $\begin{array}{l}7 \text { Volumetric available water } \\
\text { content (AWC) } \\
8 \text { Parameter a }\left[=\left(\theta_{1}+\theta_{1}\right) / 2\right]\end{array}$ & $\theta_{\mathrm{AWC}}(\%)$ & 35.52 & 51.17 & 46.30 & 45.74 & 39.83 & 39.18 & 27.72 & 20.02 \\
\hline $\mathrm{I}_{3}$, Abundant water regime & $\theta(\%)$ & - & - & - & - & 43.44 & 41.51 & 31.62 & 24.30 \\
\hline $\mathrm{I}_{2}$, Intermediate water regime & $\theta(\%)$ & 32.24 & 36.12 & 30.05 & 26.53 & 33.49 & 31.71 & 24.74 & 19.29 \\
\hline $\mathrm{I}_{1}$, Low water regime & $\theta(\%)$ & 23.36 & 23.32 & 18.48 & 15.10 & 23.53 & 21.92 & 17.81 & 14.29 \\
\hline 9 Parameter $\mathrm{b}\left[=\Delta \theta=\left(\theta_{\mathrm{u}}-\theta_{1}\right)\right]$ & & & & & & & & & \\
\hline $\mathrm{I}_{3}$, Abundant water regime & $(\Delta \theta \%)$ & - & - & - & - & 19.92 & 19.60 & 13.86 & 10.02 \\
\hline $\mathrm{I}_{2}$, Intermediate water regime & $(\Delta \theta \%)$ & 11.84 & 17.06 & 15.24 & 15.24 & 13.28 & 13.06 & 9.24 & 6.68 \\
\hline $\mathrm{I}_{1}$, Low water regime & $(\Delta \theta \%)$ & 5.92 & 8.52 & 7.72 & 7.62 & 6.64 & 6.53 & 4.62 & 2.34 \\
\hline $\begin{array}{l}\text { Lines: } \\
\text { (1) Direct measurement } \\
\text { (4) Weight fraction of dry peat plus eq } \\
\text { (2) and (5) from table } 3 \\
\text { (6) Given after multiplication of line } 4 \\
\text { (8) Line } 7 \text { respectively by } 0.75-0.50-0.2 \\
\text { (9) AWC according to fig. } 2 \text {, then multi }\end{array}$ & $\begin{array}{l}\text { ivalent perlite } \\
\times \text { line } 5 \text { and } b \\
\text { plus line } 6 \\
\text { bly by } 0.5-0.33\end{array}$ & $\begin{array}{l}\text { tribution } \\
\text { as W.P. f }\end{array}$ & r peat & & & & & & \\
\hline
\end{tabular}

number of plants per pot was used. This procedure with the programmes used (CoStat), although it indicated the significance of the interaction, did not allow to examine the corrected data. However, we could overcome this obstacle due to the fact that in none of the measurements was the disturbing effect of the number of plants per pot significant so that ordinary analysis of variance could be used.

\section{Results}

Although limited to the most interesting characteristics of the plants, a glance at Table 2 giving the mean values for the peat fractions in the mixtures (means over irrigation regimes and replications) and water regimes (means extended to peat fractions and replications) shows that highly significant effects resulting from variations in the peat fraction were much more frequent than those due to the influence of the irrigation regime.

Generally speaking, it is clear that as the peat fraction diminishes, there is a decline in productivity, leaf area, height of the plants and, when measured, stem diameter, in both series. A number of these interactions are significant. More precisely, in the peat-sand series, the decrease in leaf area due to the reduction in peat fraction is more marked going from the moister intermediate regime to the low regime. In the same series, water consumption varies irregularly, but is generally higher in the intermediate regime and decreases only when the sand fraction is at maximum. In the peat-perlite series the diameter of the stems changes only slightly with the low regime, although the small amount of perlite was found to give a significant advantage $(3.7 \mathrm{~mm}$ diameter as against $3.2 \mathrm{~mm}$ in the pure peat substrate). This advantage was retained with the intermediate regime and disappeared in the more moisture-rich regime (4.0 with peat only, 3.9 with a small perlite fraction and 2.2 with maximum perlite fraction).

As explained in the materials and methods, for the peat-sand mixtures, there was also a fertilised series without replications. For the various characteristics, certain information was obtained by processing the data on the effect of 
Table 2. Results from both series peat-sand and peat-perlite. Means for peat fractions (over water regimes and replications) and for water regimes (over peat fractions and replications); interaction significance.

\begin{tabular}{|c|c|c|c|c|c|c|c|c|c|c|c|}
\hline & & \multicolumn{4}{|c|}{$\begin{array}{l}\text { Volume ratio of peat } \\
\text { to other component }\end{array}$} & \multirow[b]{4}{*}{ Sign. } & \multicolumn{5}{|c|}{ Water supply } \\
\hline & & \multirow[t]{2}{*}{$1: 0$} & \multirow{2}{*}{\multicolumn{3}{|c|}{$\begin{array}{l}2.5: 1 \quad 1: 1 \quad 1: 2.5 \\
\text { Volume \% of peat } \\
\text { in the substrate }\end{array}$}} & & \multirow[t]{2}{*}{ Low } & \multirow[t]{2}{*}{ Interm. } & \multirow{2}{*}{\multicolumn{2}{|c|}{ Abund. }} & \multirow[b]{3}{*}{$\begin{array}{l}\text { Sign. } \\
\text { Inter }\end{array}$} \\
\hline & & & & & & & & & & & \\
\hline & & 100 & 71.4 & 50 & 28.6 & & $\mathrm{I}_{1}$ & $\mathrm{I}_{2}$ & $\mathrm{I}_{3}$ & Sign & \\
\hline \multicolumn{12}{|c|}{ Peat-sand series (not fertilized) } \\
\hline Plant total dry weight & $\mathrm{g} / \mathrm{pot}$ & 3.09 & 2.17 & 2.00 & 1.07 & $* *$ & 2.10 & 2.06 & - & ns & ns \\
\hline Leaf area & $\mathrm{cm}^{2} /$ pot & 385 & 249 & 199 & 114 & $* * *$ & 207 & 266 & - & $* * *$ & $* *$ \\
\hline $\begin{array}{l}\text { Stem height } \\
\text { (crown-apex) }\end{array}$ & $\mathrm{cm}$ & 12.6 & 11.1 & 11.7 & 9.3 & $* *$ & 11.2 & 11.2 & - & ns & ns \\
\hline $\begin{array}{l}\text { Total water } \\
\text { consumption } \\
\text { pH of soil extract }\end{array}$ & $\mathrm{cm}^{3} /$ pot & 601 & 567 & 669 & 523 & $* * *$ & 550 & 630 & - & $* * *$ & $* * *$ \\
\hline $\begin{array}{l}(1: 2.5) \\
\text { Electrical }\end{array}$ & - & 6.85 & 7.68 & 7.65 & 7.80 & $* *$ & 7.39 & 7.60 & - & ns & ns \\
\hline $\begin{array}{l}\text { conductance of soil } \\
\text { extract }(1: 2.5)\end{array}$ & $\mathrm{dSm}^{-1}$ & 0.552 & 0.133 & 0.096 & 0.067 & $* * *$ & 0.259 & 0.165 & - & ns & ns \\
\hline \multicolumn{12}{|c|}{ Peat-perlite series (fertilized) } \\
\hline Plant total dry weight & $\mathrm{g} / \mathrm{pot}$ & 2.27 & 2.41 & 1.73 & 1.09 & $* *$ & 1.64 & 2.24 & 1.74 & $*$ & ns \\
\hline $\begin{array}{l}\text { Leaf area } \\
\text { Stem height }\end{array}$ & $\mathrm{cm}^{2} /$ pot & 512 & 501 & 384 & 199 & $* * *$ & 359 & 429 & 409 & ns & ns \\
\hline (crown-apex) & $\mathrm{cm}$ & 9.6 & 9.7 & 9.4 & 7.5 & $*$ & 8.5 & 9.2 & 9.5 & ns & ns \\
\hline $\begin{array}{l}(\text { at } 3 \mathrm{~cm}) \\
\text { Total water }\end{array}$ & $\mathrm{mm}$ & 3.5 & 3.7 & 3.4 & 2.6 & $* * *$ & 3.3 & 3.2 & 3.4 & ns & $*$ \\
\hline $\begin{array}{l}\text { consumption } \\
\mathrm{pH} \text { of soil extract }\end{array}$ & $\mathrm{cm}^{3} /$ pot & 521 & 583 & 513 & 400 & $* * *$ & 408 & 543 & 562 & $* * *$ & ns \\
\hline$(1: 2.5)$ & - & 6.83 & 7.21 & 7.34 & 7.49 & $* * *$ & 7.05 & 7.29 & 7.31 & $* *$ & ns \\
\hline $\begin{array}{l}\text { Electrical } \\
\text { conductance of } \\
\text { soil extract (1: } 2.5)\end{array}$ & $\mathrm{dSm}^{-1}$ & 0.588 & 0.214 & 0.161 & 0.127 & $* * *$ & 0.392 & 0.243 & 0.182 & $* * *$ & $* * *$ \\
\hline
\end{tabular}

peat and the effect of irrigation, using their interaction as an approximate reference mean square. Broadly speaking, the results (not reported for the sake of brevity) are not significant, but generally closely agree with those of the series without fertiliser in Table 2. An other point of interest is the considerable and generalised effect of the fertiliser which gave a mean of dry matter production per pot of 5.72 $\mathrm{g} /$ pot in the series with fertiliser as against a mean of $2.08 \mathrm{~g} /$ pot (as can be seen in Table 2) in the series without fertiliser (this justifies the generalised use of fertiliser in the subsequent peat-perlite series).

Contrary to the peat fraction the effects of the irrigation was modest, often irregular and subject to interactions with the peat fraction.
This lower response to the water regime seems only in part attributable to the initial intention to intuitively reduce drought stress.

The visual examination of the soil blocks taken out of the pot in the peat-sand series at the end of the trial showed that in pots with substrate consisting of peat only for about 1.5$1 \mathrm{~cm}$ starting from the top of the pots roots were completely absent (Figure 1). These began to develop more or less uniformly throughout the volume below this level, sometimes with a slightly greater density in contact with the bottom of the pot. A similar situation, but with a slightly thinner surface layer without roots (1$0.7 \mathrm{~cm}$ ), was present in the mixture with $71.4 \%$ peat, while it was practically absent in mixtures poorer in peat, all more uniformly explored by 
Patruno A., Cavazza L., Cirillo E.

Table 3. Measurements of mechanical traits of the soil at the end of the growing period

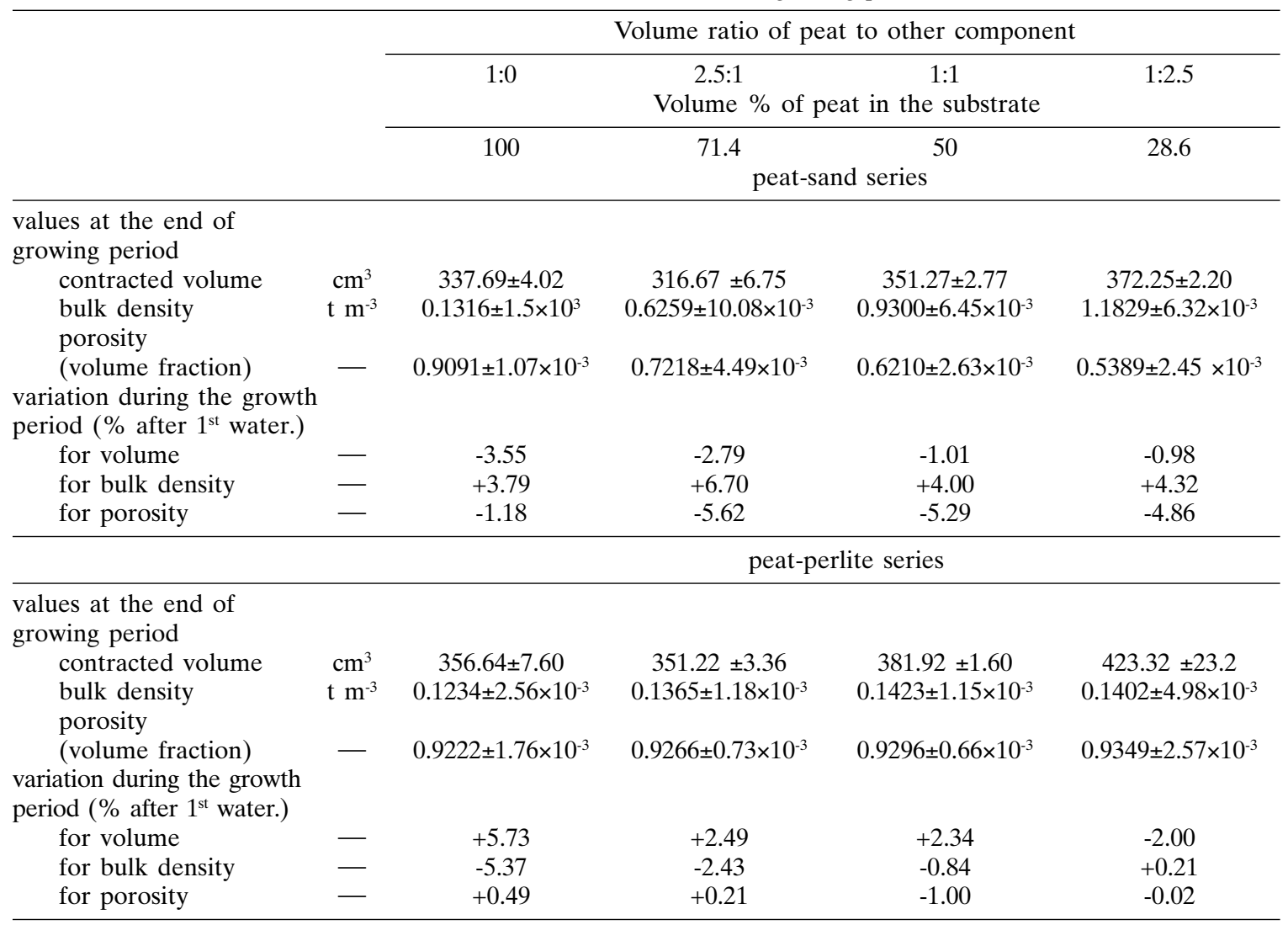

- after the mean value, its error is given

the roots. These observations suggest that in the mixtures with, or nearest to, the highest percentage of peat, the lower water conductivity of the substrate facilitates drying out and possibly a salt accumulation from the peat at the surface layer, making it hostile to local root development and probably determining a mulch effect to the benefit of the underlying layers.

In terms of the mechanics of the substrates, Table 3 shows that during cultivation there was further settling in the peat-sand series, although relatively minor with respect to the compaction which took place after wetting the pots for the first time $(-3.6 \%$ with pure peat and about $-1 \%$ with 28.6 peat), but the final porosity was (as already after the first watering), reduced from $91 \%$ with the peat to $54 \%$ with the greatest quantity of sand (this was already noted by Bragg and Chambers, 1988). In the peat-perlite series, on the other hand, there was a slight expansion in the volume of substrate (from +5.7 with pure peat and $-2 \%$ with the maximum of perlite), probably due to greater root growth. The porosity of the mixtures remained in these last cases almost constant at about $92.5 \%$ for the entire series.

Regular differences were found in the characteristics of the substrates, presented in Table 2 . The essential characteristics of the peat dominate in both series: the $\mathrm{pH}$ was slightly below neutral (about 6.84) in the first substrate then gradually increased a little more in the sand (up to 7.80) and a little less in the perlite (up to 7.49). The residual moisture content at the end of the trial (data not included for the sake of brevity) dropped from $146 \%$ to $19 \%$ in the peat-sand series and from 224.2 to $114 \%$ in the peat-perlite series, in accordance with the high water retention capacity of peat and the poor capacity of sand.

The salinity, as EC, decreases from about $0.570 \mathrm{dS} \mathrm{m} \mathrm{m}^{-1}$ in the pure peat to 0.067 in the mixture richest in sand and 0.127 in the mixture richest in perlite. This is largely an effect of di- 
lution of the salinity normally present in the peat which, however, in the case of the series with perlite, also drops as the water regime increases and decreases more rapidly going from the first to the second substrate, in particular with the low water regime (interaction significant $0.001 \mathrm{P}$ ): the peat in the low regime has values reaching $0.9 \mathrm{dS} \mathrm{m}^{-1}$, while these drop to a minimum of about $0.1 \mathrm{dSm}^{-1}$ with maximum of perlite at the moister water regime. (Values not given in details for brevity).

\section{Conclusions}

Examination of the results of growing tomato seedlings on substrates varying in the percentage of peat and sand or peat and perlite shows the clear superiority of peat only or of mixtures with $71.4 \%$ volume of peat in the mixture (commercial products). The various agronomical characteristics worsen when more sand or perlite is added to the mixture. The surface layer of pots with $100 \%$ or $71.4 \%$ peat are not explored by the roots, probably due to surface drying or salinization.

The three water regimes compared did not generally produce great effects and only a few interactions with the percentage of peat. This is apparently attributable largely to the choice of the three water regimes, selected empirically to compensate for the lower mean moisture levels to which the plantlets were exposed by higher irrigation frequency. The matter requires further in depth study, although the results suggest that the concern not to expose the plantlets to excessive water stress is already a good guideline for regulating the water regime.

Settling of the substrates in the pots during the growing period was noted, with reduction of the already low porosity of the mixtures with the sand (overall porosity about $91 \%$ that of peat alone, while it drops to just $54 \%$ when the peat drops to about $30 \%$ in volume in the mixture). In the mixtures with perlite, the variations in porosity were low (from about $92 \%$ to $93 \%$ ). The mixtures are dominated by certain characteristics of the peat (for example, the hygro- scopicity, slightly subacid $\mathrm{pH}$ and above all salinity), the latter interaction with the water regime, in the mixtures with perlite reaching concentrations of $0.9 \mathrm{dS} \mathrm{m} \mathrm{m}^{-1}$ in the pots with peat only and a low water regime.

\section{Acknowledgements}

The Authors thank En Teodor Herrero i Carbò and Mònica Hernandis i Ferrando, who as Erasmus, fellows actively collaborated in the growing phase of the experiments.

\section{References}

Bragg W.C., Chambers B.J. 1988. Interpretation and advisory applications of composts air filled porosity (AFP) measurements. Acta Hortic., 221:34-44.

Cavazza L., Patruno A., Cirillo E. 2005. An approximate indirect evaluation of water retention relationship for small pots. Adv. Hort. Sci., 19:111-115.

De Boodt M.F., Verdonck O.F., Cappaert I.M. 1974. Method for measuring the water release curve of organic substrates. Acta Hortic., 37:2054-2062.

Fisher P.Y. 1985. Aspetti e problemi dei substrati a base di torba. Colture Protette, 4:36-40.

Gras R. 1987. Propriété physiques des substrates. In: Les Cultures Hors Sol, ouvrage collectif dirigé par D. Blanc, 79-123. INRA (Ed.), Paris.

Lenzi A., Oggiano N., Maletta M., Bolaffi A., Tesi R. 2001. Caratteristiche fisiche e chimiche di substrati a base di perlite, pomice e torba. Italus Hortus, 8:23-31.

Morel P., Poncet L., Rivière L.M. 2000. Les support de culture horticoles. INRA (Ed.), Paris, 87 pp.

Patruno A., Cavazza L., Cirillo E. 2005. Caratteristiche fisiche di miscugli binari di torba e sabbia o perlite. Agroindustria, 4:185-197.

Tepe W. 1953. Phisikalische und chemische Untersuchungen von gaertnerischen Kulturerden. Z. Planzenernaehr. Bodenkd., 63:222-235.

Tesi R. 1984. Substrati in ortofloricoltura. Colture Protette, 12:23-28.

Tesi R., Tognoni F., Giustiniani L. 1985. Caratteristiche fisiche e fisico-chimiche dei substrati destinati alle colture in contenitore. Colture Protette, 4:21-27.

White J.W. 1964. The concept of "container capacity" and its application to soil moisture fertility regimes in the production of container grown crops. Ph. Dissertation. The Pennsylvania ST. Univ. (cited by Lenzi et al. 2001). 